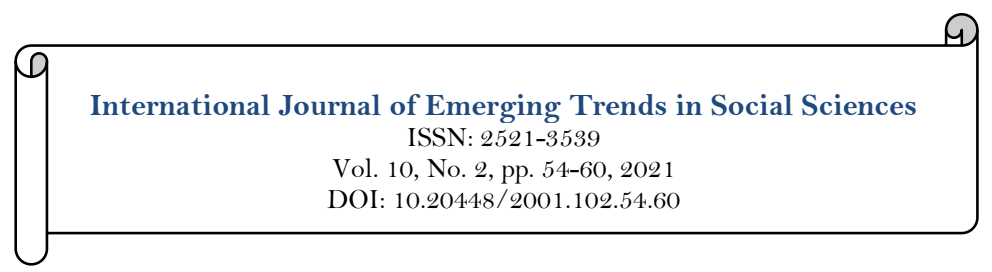

\title{
A Study on the Impact of Quantitative Easing Monetary Policy of the United States on China's Economy
}

\author{
Xin Kai \\ Ph.D Candidate, School of Economics, Central University of Finance and Economics, Changping District, Beijing, China. \\ Email:kaixin@email.cufe.edu.cn
}

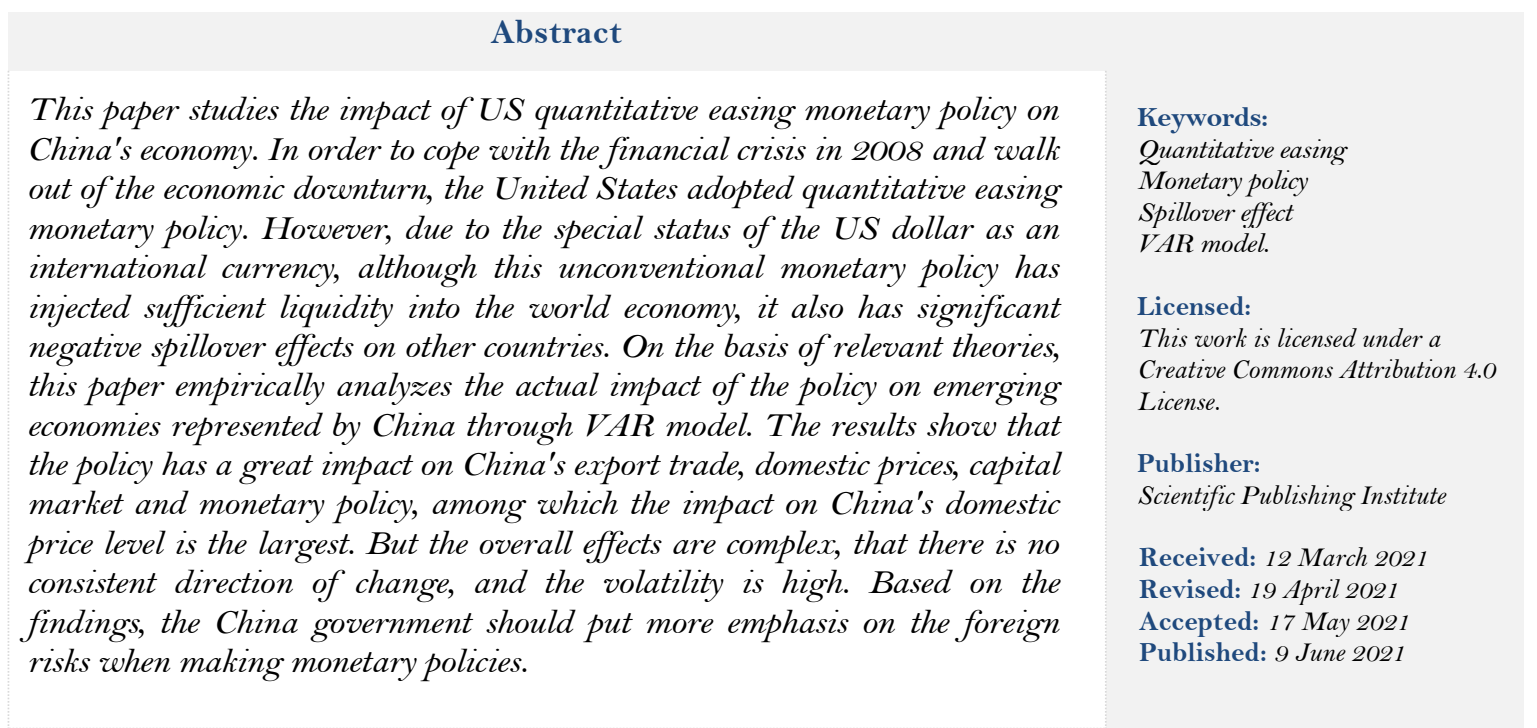

Funding: This study received no specific financial support.

Competing Interests: The author declares that there are no conflicts of interests regarding the publication of this paper.

\section{Introduction}

In 2008, the financial crisis caused by the US subprime mortgage crisis led to a sharp decline in global economic growth. On the basis of the experience of the great depression from 1929 to 1933, the US Federal Reserve took effective measures to deal with it: implemented the non-traditional monetary policy, namely quantitative easing, with the balance sheet as the operation tool monetary policy to stimulate economic growth. However, due to the development of economic globalization and the special status of the US dollar as an international currency, the monetary policy of the Federal Reserve has a great spillover effect on other countries. On the positive side, sufficient liquidity alleviates the negative impact of the crisis. On the negative side, this extremely loose monetary policy will lead to the depreciation of the US dollar and global hot money flow, which will have a negative impact on the world economy and the emerging economies represented by China, and also bring great fluctuation.

Therefore, on the basis of relevant literature and theory, this paper will use empirical methods to study the real impact and spillover effect of the US quantitative easing monetary policy on China's economy. The rest of this paper will be as follows: the second part is the literature and theories review, the third part is the empirical analysis of the impact of the US quantitative easing monetary policy on China, and the fourth part is the conclusion. 


\section{Literature and Theory Review}

This part will review the concept, theoretical basis and literature of spillover effect of quantitative easing monetary policy.

\subsection{The Concept of the Quantitative Easing Monetary Policy}

Quantitative easing monetary policy (QE) was first proposed around 1990s in an academic conference, and the concept of $\mathrm{QE}$ is to express a new monetary stimulus policy implemented by the central bank, that is to stimulate economic recovery fully by creating credit. At present, there is no unified definition of $Q E$, but scholars generally believe that in the case of economic recession and the traditional monetary policy fails, it injects liquidity and basic money through unconventional ways such as purchasing long-term bonds in the secondary market, so as to stimulate economic recovery, which is called QE. "Quantitative" refers to the creation of a certain amount of base money, while "ease" is to provide sufficient liquidity to financial institutions and markets.

There are many researches on quantitative easing monetary policy, mainly based on the failure of traditional monetary policy. Krugman (2000) pointed out that the key to get rid of the liquidity trap is for the central bank to make a credible commitment to continuous expansionary monetary policy in the future, and QE plays an important role in changing people's expectations and increasing the credibility of the central bank's commitment. Bernanke and Reinhart (2004) discussed three strategies for the central bank to stimulate the economy under the condition of zero interest rate: reshaping the interest rate expectation, changing the structure of the central bank's balance sheet and enlarging the scale of the central bank's balance sheet. Kiyotaki and Moore (2012) believe that when faced with liquidity shocks, the central bank should adopt QE and purchase specific assets, change the structure of assets held by the private sector, and ease the financing constraints of enterprises, which is conducive to the increase of enterprise investment and economic recovery.

\subsection{Literature on the Spillover Effects on Monetary Policy}

The spillover effect of monetary policy mainly affects other countries from two aspects: one is the increase of domestic liquidity and income, so as to increase the import to foreign countries and promote the increase of foreign output. The other is that the increase of domestic liquidity leads to the devaluation of currency, so as to optimize domestic terms of trade, reduce foreign exports and reduce output.

QE of the US influences China's economy mainly in three ways. First, foreign trade channels. Tan (2010) believes that the US economic recovery will increase import demand and improve China's export environment. At the same time, it will also increase China's foreign exchange reserves, which will lead to China's foreign exchange account and face greater inflationary pressure. Second, commodity price channels. He (2012) pointed out that the depreciation of the US dollar caused by QE of the US will lead to the rise of commodity prices in US dollar terms, thus causing imported inflation to China. The third is the channel of short-term capital flow, which has a complex influence. Pan and Liu (2012) believe that QE of the US keeps the domestic interest rate at zero level, while emerging economies such as China keep the interest rate at a high level in order to curb inflation, resulting in the influx of hot money.

From the current research situation, we can see that scholars have many researches on the theoretical basis and transmission mechanism of monetary policy, but there is no consistent conclusion on the spillover effect of QE. In addition, on December 22, 2016, the Federal Reserve announced the second interest rate increase, which marked the withdrawal and systematic completion of the US QE, and some early studies lacked timeliness. Therefore, the next part will use empirical methods to comprehensively quantify the actual impact of QE on China's economy.

\section{Empirical Analysis of the Impact of the US's QE on China's Economy \\ 3.1. Variable Selection and Description \\ 3.1.1. US QE Data}

Since the essence of QE of the US is to inject liquidity into the economy, this paper selects the monthly data of broad money supply in the United States (recorded as USM2) to show the effect of QE of the US, which is from the Federal Reserve website.

\subsubsection{China's Economic Data}

For the impact on China's economy, this paper focuses on the impact on China's foreign trade, domestic price level, capital market and monetary policy. In order to reduce the overlap of variables and for the sake of data availability, this paper selects China's total export value (recorded as CNEX), consumer price index (recorded as CNCPI), one-year Shanghai interbank offered rate (recorded as SHRY) and broad money supply (recorded as $\mathrm{CNM} 2$ ) to reflect the specific impact of China's foreign trade, price level, capital market and monetary policy Variable. The data of CNEX, CNCPI and CNM2 are from the National Bureau of statistics of China, and SHRY is from the official website of Shanghai interbank offered rate. All variables are monthly data. 
As for the time range of economic data of the two countries, this round of $\mathrm{QE}$ of the Federal Reserve started in November 2008 and ended in October 2014. However, due to the time lag of the impact of economic variables, in view of the integrity of the policy cycle, this paper selects all variables from November 2008 to December 2015, that is, the Fed's first interest rate increase after this round of QE, which means the complete termination of this round of $\mathrm{QE}$.

\subsection{Model Setting}

This paper will use vector autoregression model(VAR). VAR model does not focus on the explanation of estimated parameters, but studies the dynamic relationship among multiple variables through impulse response and variance decomposition. The general form of VAR model is as follows,

$$
y_{t}=A_{1} y_{t-1}+\cdots+A_{p} y_{t-p}+B_{1} x_{t}+\cdots+B_{r} x_{t-r}+\varepsilon_{t}
$$

Where, $y_{t}, x_{t}$ is the vector of endogenous and exogenous variables respectively, $p$ and $r$ are the order of $\mathrm{lag}, \varepsilon_{t}$ is a random perturbation term. The equation shows that in VAR system, one (endogenous) variable is determined by its own lag term and other (exogenous) variables and their lag terms at the same time.

\subsection{Model Testing}

In this paper, we will construct four models with USM2 as the independent variable, and CNEX, CNCPI, SHRY and CNM2 as the dependent variables separately. As VAR model must satisfy some assumptions, it should be tested before further analysis.

\subsubsection{Variable Stationarity Test}

Financial variables usually have a certain time trend, which will lead to estimation errors. In this paper, we use the augmented Dickie-Fuller test (ADF) to test the stationarity of the above five time series variables, and the result is that the five variables are not stationary. The results of ADF test after the first-order difference of five variables are stable. Therefore, all variables are treated by first order difference "D". The test results are shown in the Table 1.

Table-1. Results of the Test for Variable Stationarity.

\begin{tabular}{c|c|c|c|c|c|c}
\hline Variables & ADF-value & $\mathbf{1 \%}$ threshold & $\mathbf{5 \%}$ threshold & $\mathbf{1 0 \%}$ threshold & p-value & Result \\
\hline USM2 & 1.664 & -5.532 & -2.903 & -2.586 & 0.9980 & Unstable \\
\hline DUSM2 & -7.427 & -5.534 & -2.904 & -2.587 & 0.0000 & Stable \\
\hline CNEX & -2.577 & -5.532 & -2.903 & -2.586 & 0.0979 & Unstable \\
\hline DCNEX & -11.562 & -5.534 & -2.904 & -2.587 & 0.0000 & Stable \\
\hline CNCPI & -1.453 & -5.532 & -2.903 & -2.586 & 0.5565 & Unstable \\
\hline DCNCPI & -10.118 & -5.534 & -2.904 & -2.587 & 0.0000 & Stable \\
\hline SHRY & -1.001 & -5.532 & -2.903 & -2.586 & 0.7527 & Unstable \\
\hline DSHRY & -5.383 & -5.534 & -2.904 & -2.586 & 0.0000 & Stable \\
\hline CNM2 & 0.289 & -5.532 & -2.903 & -2.586 & 0.9769 & Unstable \\
\hline DCNM2 & -10.506 & -5.534 & -2.904 & -2.586 & 0.0000 & Stable \\
\hline
\end{tabular}

3.3.2. Determination of Lag Order and Cointegration Test

According to AIC and SIC criteria, the lag orders of DUSM2 with DCNEX, DCNCPI, DSHRY and DCNM2 are determined to be 3, 4, 3 and 5 orders respectively. By Johansen cointegration test, DUSM 2 and the other four variables all have a long-term equilibrium relationship respectively.

\subsubsection{Stability Test of VAR Model}

Before impulse response and variance decomposition analysis, it is necessary to test the stability of VAR model. The main method is unit root test, that is, the reciprocal of all unit root modules of VAR model is less than 1. As shown in Figure 1, the unit roots of VAR models are all in the unit circle, which means that the four VAR models are stable.

\subsection{Impulse Response Analysis}

Impulse response describes the impact on the current and future values of all endogenous variables after a standard deviation impact is imposed on the random error.

\subsubsection{The Response of China's Foreign Trade to the Pulse of the US's QE}

As can be seen from Figure 2, when a positive standard deviation shock was given to the US broad money supply, China's gross export value made a negative response to this disturbance at the moment, and the negative response strengthened and reached the bottom in the second period, and the bottom rebounded to be positive in the third period, then began to fluctuate slightly, and stabilized in the tenth period. 


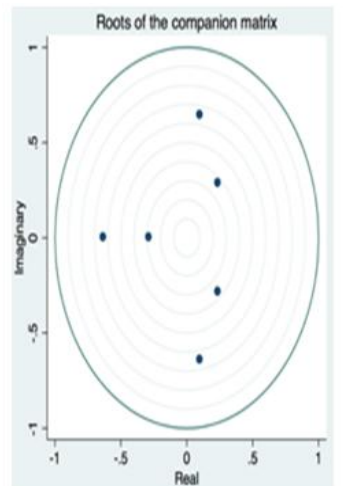

a.DUSM2 \& DCNEX

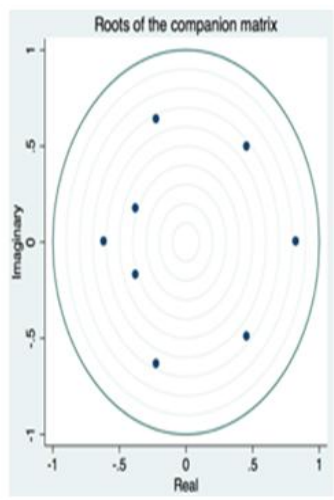

b.DUSM2 \& DCNCPI

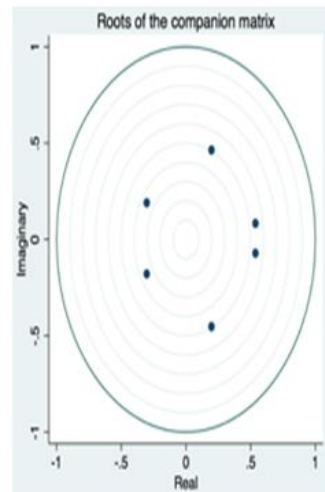

c.DUSM2 \& DSHRY

Figure-1. Stability Test of VAR Model

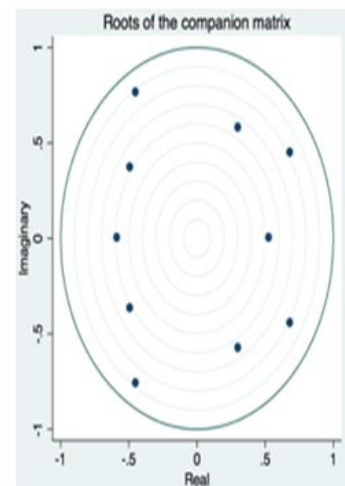

d.DUSM2 \& DCNM2

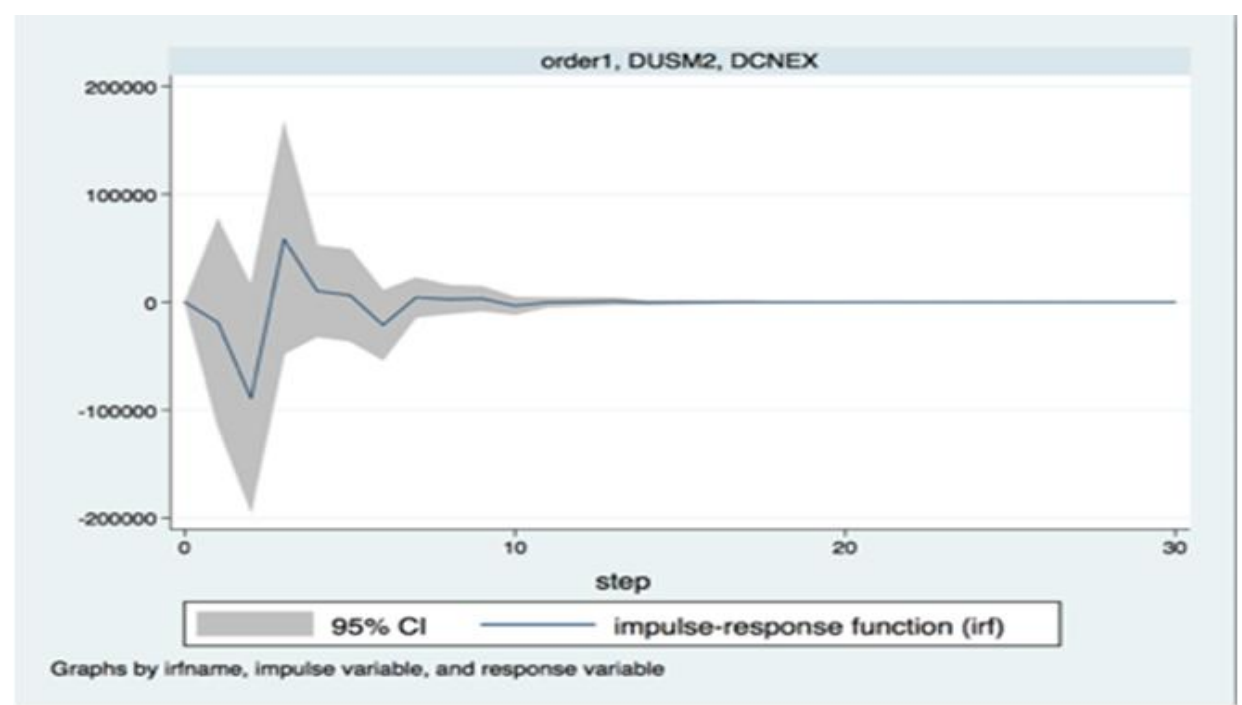

Figure-2. Impulse response of China's total export value to US broad money supply.

Therefore, it can be concluded that the impact path of US's QE on China's foreign trade is that it initially has a negative impact and intensifies, then it starts to rebound and has a positive impact, but the degree is not as good as the negative impact at the beginning. This is in line with the expectation that the depreciation of the US dollar will worsen China's foreign trade conditions, and the ability of world economic recovery to drive China's foreign trade growth is lower than that of RMB appreciation to worsen trade.

\subsubsection{The Response of Chinese Price Level to US's QE Impulse}

As can be seen from Figure 3, when the broad money supply of the US is given a positive standard deviation shock, the consumer price index of Chinese residents has made a negative response and rose to a positive value in the second period. After a significant decline in phase 3, it rebounded again in the fourth period, but it was negative. After the fifth period, it fluctuates slightly and tends to be stable gradually.

Therefore, it can be concluded that US's QE has a negative impact on China's price level, and it fluctuates a lot in the early stage. This is not in line with the expectation that the depreciation of the US dollar will lead to the rise of international bulk goods prices and lead to China's imported inflation. The possible reason is that China is greatly affected by the world economic depression, and because China is in the period of economic restructuring and transformation, the economic growth rate slows down, resulting in the price level in the downward channel.

\subsubsection{Impulse Response Results of Chinese Capital Market to US's QE}

As can be seen from Figure 4, when a positive standard deviation shock was given to the US broad money supply, the one-year Shanghai interbank offered rate immediately made a negative response and rebounded to a positive value in the 2 nd period. In the third stage, it decreased to a negative value, and gradually increased from the fourth stage, but all of them were negative, and tended to be stable in the tenth stage. 


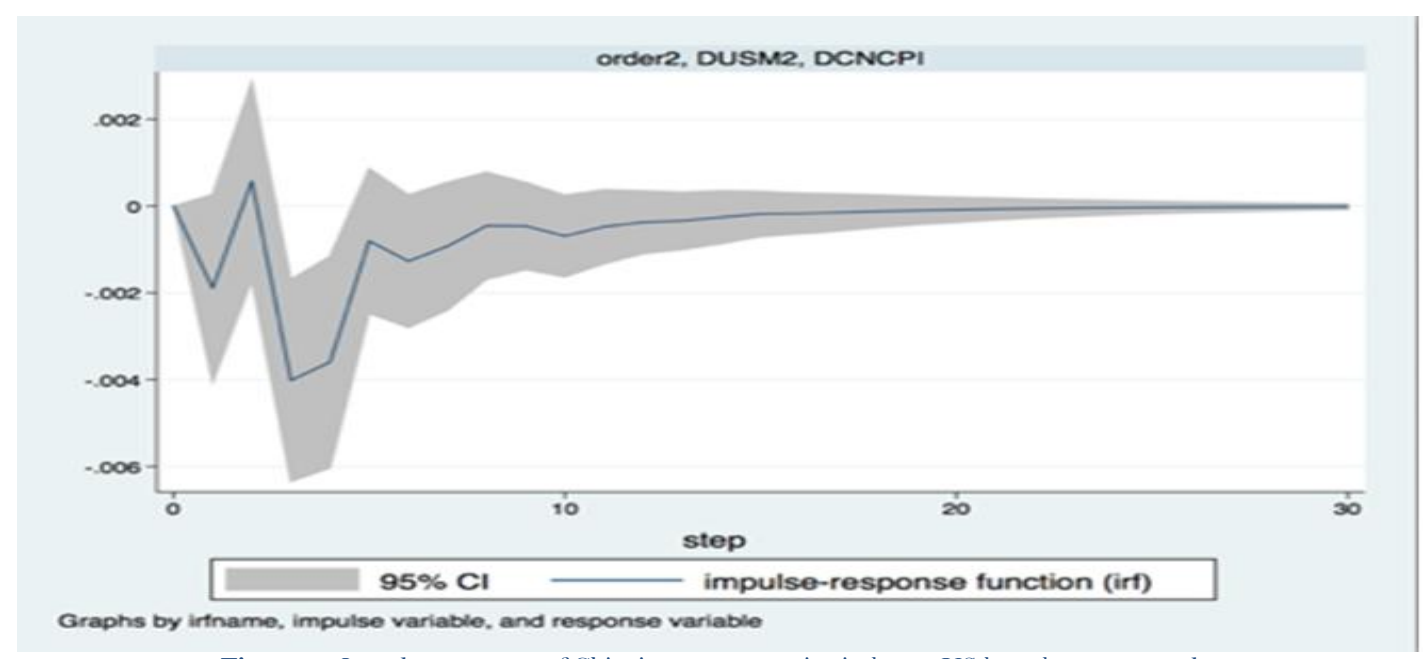

Figure-3. Impulse response of China's consumer price index to US broad money supply.

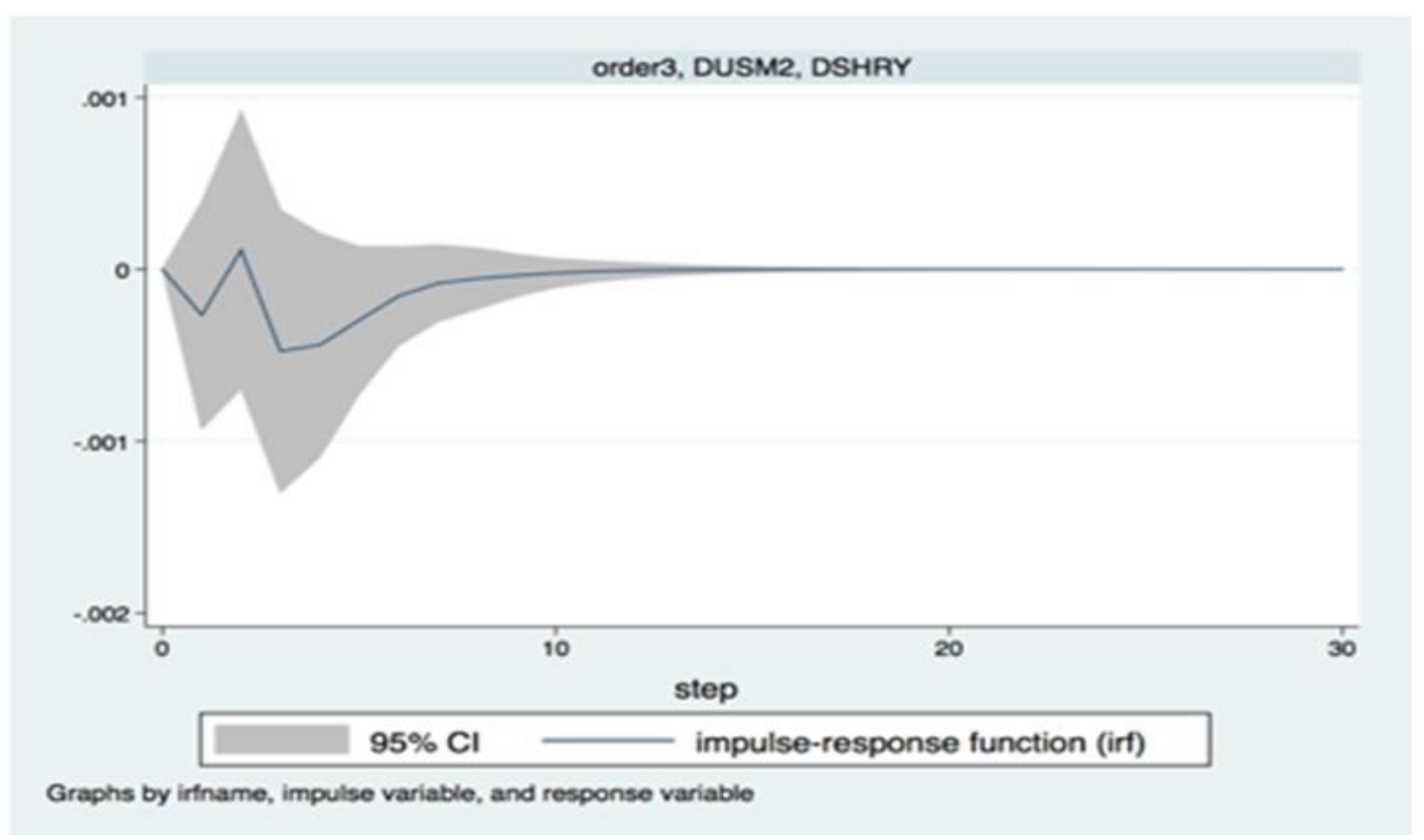

Figure-4. Impulse Response of one year Shanghai interbank offered rate to the broad money supply of the US.

Therefore, it can be concluded that US's QE has a negative impact on China's interest rate, which is manifested in the path of interest rate reduction, rebound, re-bottoming and slow recovery. This is due to the zero interest rate policy of the US, which leads to the inflow of hot money into China, and leads to the fluctuation of China's interest rate and capital market, and lowers China's interest rate level in the short term. At the same time, with the tightening and withdrawal of QE of the US and the recovery of China and the world economy, the interest rate will be in the upward channel.

\subsubsection{Impulse Response of China's Monetary Policy to US's QE}

As can be seen from Figure 5, after giving a positive standard deviation shock to the US broad money supply, China's broad money supply made a slight negative response in the early stage, and then began to rise sharply in the third period, and then began to fall back. After becoming negative in the eighth period, China's broad money supply began to fluctuate around zero, and began to stabilize in the 20 th period.

Therefore, it can be concluded that the QE of the US mainly has a positive impact on China's monetary policy, which is consistent with the expectation that the loose monetary policy of the US will cause a global competition for loose monetary policy and currency devaluation. In order to prevent excessive interest rate spread, excessive hot money inflow, reduce the adverse impact of the depreciation of the US dollar on China's foreign trade, and deal with domestic problems such as high domestic debt and economic downturn, China chooses a moderately loose monetary policy. 


\subsection{Analysis of Variance Decomposition}

The variance decomposition analysis of VAR model mainly reveals the proportion of changes caused by the impact of the series itself and other series.

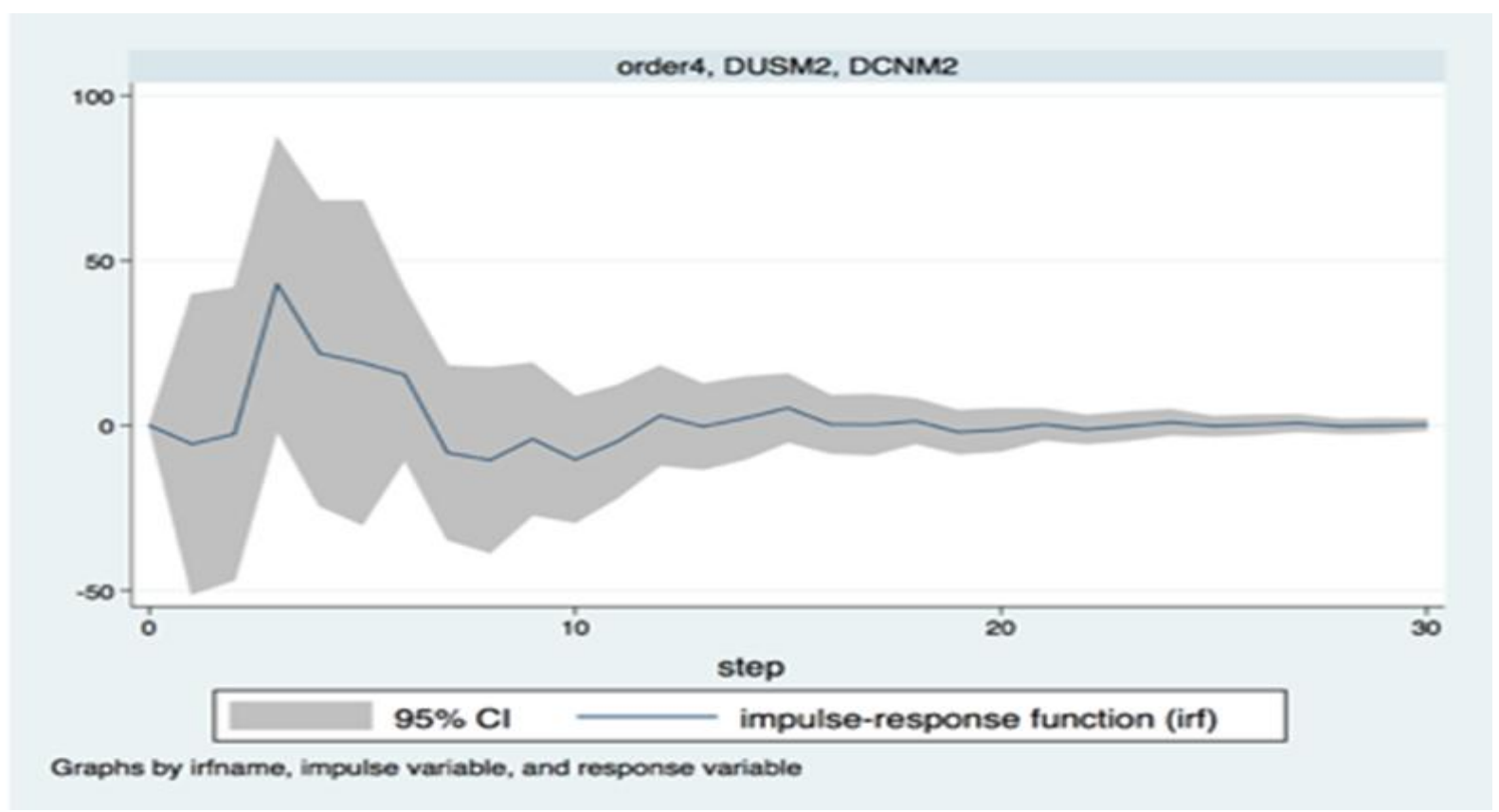

Figure-5. Impulse response of China's broad money supply to US broad money supply.

As can be seen from Table 2, among the effects of the increase in the US broad money supply on China's economic variables, the most powerful explanation for China's CPI is about 25\%, followed by China's broad money supply of $7.33 \%$, China's total export value of $6.9 \%$ and one-year Shanghai interbank offered rate of $3.7 \%$. In terms of the duration of shock fluctuation, the impact of the U.S. broad money supply on China's CPI fluctuates the most, and it does not stabilize and reach the peak until the 2oth period, while the other variables tend to stabilize and reach the peak around the 10th period.

Table-2. Variance Decomposition of China's economic indicators impacted by US's QE.

\begin{tabular}{c|c|c|c|c}
\multicolumn{5}{c}{ Table-2. Variance Decomposition of China's economic indicators impacted by US's QE. } \\
\hline Lag order & DCNEX & DCNCPI & DSHRY & DCNM2 \\
\hline 1 & 0.0126 & 0.0220 & 0.0003 & 0.0305 \\
\hline 2 & 0.0176 & 0.0653 & 0.0039 & 0.0296 \\
\hline 3 & 0.0558 & 0.0689 & 0.0049 & 0.0299 \\
\hline 4 & 0.0674 & 0.1711 & 0.0188 & 0.0486 \\
\hline 5 & 0.0670 & 0.2332 & 0.0305 & 0.0647 \\
\hline 6 & 0.0671 & 0.2366 & 0.0355 & 0.0742 \\
\hline 7 & 0.0689 & 0.2402 & 0.0368 & 0.0747 \\
\hline 8 & 0.0689 & 0.2434 & 0.0372 & 0.0721 \\
\hline 9 & 0.0689 & 0.2439 & 0.0373 & 0.0732 \\
\hline 10 & 0.0690 & 0.2446 & 0.0374 & 0.0732 \\
\hline 11 & 0.0690 & 0.2463 & 0.0374 & 0.0738 \\
\hline 12 & 0.0690 & 0.2473 & 0.0374 & 0.0742 \\
\hline 13 & 0.0690 & 0.2478 & 0.0374 & 0.0733 \\
\hline 14 & 0.0690 & $0.2482^{1}$ & 0.0374 & 0.0732 \\
\hline
\end{tabular}

Therefore, it can be concluded that the growth of US broad money supply caused by QE has less influence on China's foreign trade, capital market and monetary policy, and the corresponding fluctuation time is shorter. The explanation of price level change is the strongest, and the time to reach the peak is the longest.

\section{Conclusions}

From the empirical analysis, the impact of QE on China is complex. The influence of US's QE on China's foreign trade, price level, capital market and monetary policy is no single positive or negative, but fluctuating,

${ }^{1}$ Limited by the length of the article, the result of the variance decomposition of CNCPI is not fully displayed. The impact of CNCPI tends to be stable in the 20th period and reaches the maximum value of 0.2489 . 
that is, the game of different factors in the influence path. From the perspective of variance decomposition, the US's QE can partly explain the changes of China's economic indicators, among which the impact on China's price level is the greatest.

Generally speaking, the theoretical analysis and empirical results are consistent, that is, with the deepening of China's economic openness, the linkage between China's economy and the world economy, especially the US is becoming much tighter, the interaction factors are also very complex, there are many uncertain factors, and the results and performance are complicated.

\section{References}

Bernanke, B. S., \& Reinhart, V. R. (2004). Conducting monetary policy at very low short-term interest rates. American Economic Review, 94(2), 85-90. Available at: https://doi.org/10.1257/0002828041302118.

He, Z. Q. (2012). Impacts of American quantitative easing monetary policy on China's inflation. Finance and Economics, 10, 1-11. Available at: https://doi.org/10.3969/j.issn.1000-8306.2012.10.001.

Kiyotaki, N., \& Moore, J. (2012). Liquidity, business cycles, and monetary policy. National Bureau of Economic Research Working Paper, No. w 17934.

Krugman, P. (2000). Thinking about the liquidity trap. Journal of the Japanese and International Economies, 14(4), 221 1-237. Available at: https://doi.org/10.1006/jjie.2000.0458.

Pan, C. F., \& Liu, G. (2012). Quantitative easing, international capital flows and the international coordination of monetary policy. Reform, 4, 84-91. Available at: https://doi.org/CNKI:SUN:REFO.0.2012-04-014.

Tan, X. F. (2010). The exit strategy of fed quantitative easing monetary policy and its effect on China. Studies of International Finance, 2, 26-37. Available at: https://doi.org/CNKI:SUN:GJJR.0.2010-02-005. 